\section{Evolution of Rifting in Africa}

WhIte not disagreeing with Girdler el al.'s basic premise of thinning and breaking up of the African plate, I cannot see how the increase in age of rift faulting and vulcanicity of the East African rift valleys away from the rift can be compared with the increase in age of islands on the oceanic floor away from mid-oceanic ridges. Tho latter phenomena can be explained by crustal movement away from the midoceanic ridge, which remains the centre of seismic activity, whereas in East Africa there is certainly no corresponding increase in age of rocks away from the rift valleys. Could not the apparent increase in age of seismic activity away from the centres of the rift valleys be explained more simply?

Consider the hypothesis, which seems very reasonable, that there is (and was) more seismic activity at the centre of the rift valleys than away from them. If this was so, records of seismic activity taken over any time interval would show more seismic activity at the centre than away from it and, unless the end of the measured time interval happencd to coincide with the rare seismic event which occurs away from the rift, the probability is that measurements would show that the more recent seismic events occur at the centre of the rift, as indicated by Girdler et al.'s Figs. 3 and 4. In fact the irregularity of distribution in Figs. 3 and 4 would further support this hypothesis.

It thus seems that the apparcnt increase in age of seismic activity with incrcasing distance from the centre of the East African rift valleys can be explained simply by supposing that the centre of the rift valley is the ecntre of seismic activity.

\section{R. B. KING}

Land Resources Division,

Directorate of Overseas Surveys,

Tolworth Tower,

Surbiton,

Surrey.

Received January 19, 1970.

${ }^{1}$ Girdlor, R. W., Fairhead, J. D., Searle, R. C., and Sowerbutts, W. T. C., Nature, 224, 1178 (1989).

\section{Wave Formation between Impacting Liquids in Explosive Welding and Erosion}

IN a study of impacting liquid sheets using high speed photography, we have observed the development of a wave pattern along the interface between the colliding liquids. The waves were similar to those reported in other studies on impact, notably in explosive welding of metal plates ${ }^{1}$, in ballistic impact ${ }^{2,3}$ and in the erosion of metal surfaces under the high speed impact of liquid drops ${ }^{4}$. Explanations concorning the wave patterns found. in these investigations have been based on a study of the deformed and wavy surface after impact. Sorious practical difficulties havo usually prevented observation of the collision interface during the event. The technique to be described, however, has just this advantage, namely that waves can be observed to form during the impact. The fact that the collision occurs at low velocities between liquids need not seriously detract from the usefulness of the model. In the more extreme conditions of high velocity impact with solids, the impact pressure is sufficiently high compared with the flow stress of the solid that the problem is treated hydrodynamically anyway.

Before describing the experiments with impacting liquids we give a brief account of wave formation and jetting in cases involving solids. An arrangement for explosive weld formation is shown in Fig. 1. A flyor plate is accelerated obliquely against a stationary parent plate by a sheet of explosive detonated on the upper surface of the flyer plate. Under the high impact pressure the flyer plate flows in the manner of an impinging jet, dividing into two streams and forming with the parent plate a thin high velocity re-entrant jet and a slower salient jet, each moving to the right. The high velocity of the re-entrant jet over the plato is responsible for bringing about the intimate contact and welding of the two metals. A characteristic feature of welds formed in this way is that within a certain range of the included angle $\alpha$-typically $5^{\circ}$ to $20^{\circ}$-waves are produced along the interface. Fig. $2 \alpha$ shows an example from the work of Bahrani, Black and Crossland ${ }^{1}$ of waves in an $\alpha$ brass to mild steel weld.

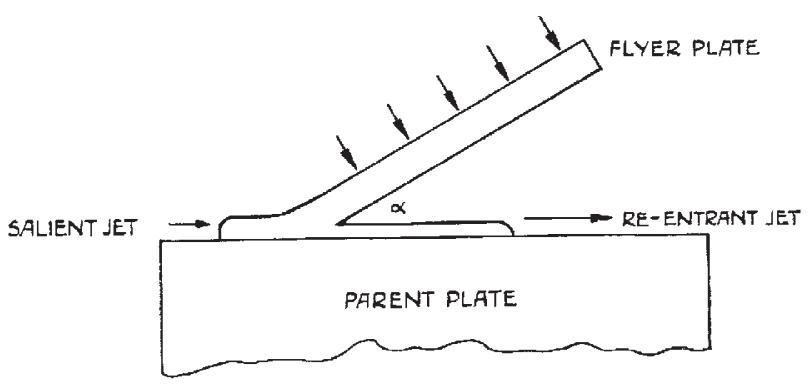

Fig. 1. A typical arrangement for producing explosive welding.

In drop impingement damage, found in practice in the rain erosion of high speed aircraft and in steam turbine blade erosion by wet stcam ${ }^{5}$, waves form in solids under the jetting action of liquid flowing outwards from the centre of the impact area ${ }^{4}$. This liquid shears the surface of the solid into waves and ripples along the boundary of the impact area. Fig. $2 b$ shows a section through a wavy region of this kind in aluminium. An enlargement of the waves appears in Fig. $2 c$.

Wave formation in the examples given above is associated with jetting of the impacting plate or drop. Jet formation in explosive impact has becn described in a woll known theory due to Birkhoff, MacDougall, Pugh and Taylor ${ }^{6}$. For the arrangement in Fig. 1 it can be shown that when the flow is incompressible the re-entrant jet velocity is given by $V(\cot \alpha+\operatorname{cosec} \alpha)=V \cot \frac{\alpha}{2}$ and the stagnation pressure by $\frac{1}{2} \rho V^{2} \cot ^{2} \alpha$, where $V$ is the impact velocity. For small values of $\alpha, V \cot \alpha$ becomes supersonic. Taking this and the compressibility of the solid into account it is found that there is a lower critical value of $\alpha=\alpha_{c}$ below which a jet cannot form ${ }^{7,8}$. A similar description has been applied to liquid drop impact4. The jetting velocity is again $V$ cot $\frac{\alpha}{2}$ and the edge stagnation pressure is now $\frac{1}{2} \rho V^{2} \operatorname{cosec}^{2} \alpha$, where $V$ is the impact velocity normal to the surface and $\alpha$ the re-entrant angle betwcen the rounded front of the drop and the solid. In the same way and in the same conditions as for explosive impact it has been shown that there is a lower limit to $\alpha$ for jet formation with liquid drops ${ }^{9}$. The system used to oxamine the impact between liquids is shown in Fig. 3. Three clear sheets of 'Perspex' were clamped tightly together sandwich-fashion. The central sheet, $1.5 \mathrm{~mm}$ thick, had a piece cut away such that when the two outer sheets were in position the gap remaining formed a flat sided chamber open at one end. A brass piston of the same section as the chamber fitted into the open end. Clear and opaque (dyed) volumes of water were injected through the outer cover sheet into the chamber in the positions shown in the figure. Fine lines seribed in wax on the cover sheets enabled the two shcets of water to maintain a straight liquid/air interface at the appropriate included angle. The impact between the two liquid sheets was produced by moving the brass piston inwards at a 